\title{
Bleeding Risk in Nonvalvular Atrial Fibrillation Patients Receiving Direct Oral Anticoagulants and Warfarin: A Systematic Review and Meta-Analysis of Observational Studies
}

\author{
Yimin Pearl Wang ${ }^{1, *}$ Rohan Kehar ${ }^{1,{ }^{*}}$ Alla lansavitchene ${ }^{2} \quad$ Alejandro Lazo-Langner ${ }^{1,3}$ (1) \\ ${ }^{1}$ Division of Hematology, Department of Medicine, Western \\ University, London, Ontario, Canada \\ 2 Library Services, London Health Sciences Centre, London, Ontario, Canada \\ ${ }^{3}$ Department of Epidemiology and Biostatistics, Western University, \\ London, Ontario, Canada

\begin{abstract}
Address for correspondence Alejandro Lazo-Langner, MD, MSc, FRCPC, Division of Hematology, London Health Sciences Centre, Victoria Hospital, 800 Commissioners Road E, Room E6-216, London, ON N6A 5W9, Canada (e-mail: alejandro.lazolangner@lhsc.on.ca).
\end{abstract}

TH Open 2020;4:e145-e152.

\begin{abstract}
Keywords

- atrial fibrillation

- direct oral anticoagulants

- bleeding

- observational studies

- meta-analysis

Introduction In randomized trials in atrial fibrillation (AF) patients on direct oral anticoagulants (DOACs) have a lower risk of bleeding compared with warfarin. However, data from randomized trials may not extrapolate to general population. We aimed to determine the risk of bleeding in patients on DOACs in observational studies.

Materials and Methods Observational studies from 1990 to January 2019 were included. A pooled effect hazard ratio (HR) was calculated with a random effects model using the generic inverse variance method. Subgroup analyses according to previous anticoagulants exposure, study type, funding source, and DOAC type (direct thrombin inhibitors vs. factor Xa inhibitors) were conducted.

Results A total of 35 studies comprising 2,356,201 patients were included. The average pooled HR for observational data was 0.78 (95\% confidence interval [Cl] $0.71,0.85$ ). There were no statistically significant differences in pooled HR by previous exposure to anticoagulants, DOAC type (direct thrombin vs. factor Xa inhibitors), study type, and funding source. Among patients receiving factor $X a$ inhibitors, patients on apixaban had a lower risk of bleeding compared with warfarin (HR $0.60,95 \% \mathrm{Cl} 0.50,0.71, p<0.001)$ in contrast to those on rivaroxaban (HR $0.98,95 \% \mathrm{Cl} 0.91,1.06, p=0.60$ ).

Conclusion In observational studies, AF patients on DOACs experience less bleeding events compared with warfarin; however, apixaban and dabigatran, but not rivaroxaban, have a lower risk of bleeding than warfarin.
\end{abstract}

\section{Introduction}

Atrial fibrillation (AF) is one of the most common sustained cardiac arrhythmias in the general population with a prevalence of 1 to $2 \%$ and is often associated with an increased risk

These authors contributed equally to this work.

received

March 6, 2020

accepted after revision

May 26, 2020
DOI https://doi.org/

10.1055/s-0040-1714918. ISSN 2512-9465. of death, stroke, bleeding, and other thromboembolic events. ${ }^{2}$ AF has a large influence on health care as a result of hospitalization, stroke, and other related costs. Due to the rising prevalence of $\mathrm{AF}$, proper care is needed to reduce burden and health care cost. ${ }^{3}$

Based on the North American guidelines, there are two types of AF, valvular and nonvalvular depending on whether
License terms

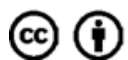

(C) 2020 Georg Thieme Verlag KG Stuttgart · New York 
there are valvular abnormalities such as the presence of mitral stenosis or artificial valves. ${ }^{4}$ The standard oral anticoagulant therapy administered to nonvalvular AF patient has typically been vitamin $\mathrm{K}$ antagonists, particularly, warfarin. ${ }^{1}$ In recent years, direct oral anticoagulants (DOACs)-including direct thrombin inhibitors (DTI) and direct factor Xa (FXa) inhibitors-have become an alternative to warfarin due to its relatively stable pharmacokinetics ${ }^{5}$ resulting in no need for laboratory monitoring and less pharmacological interactions compared with warfarin. ${ }^{6}$

Randomized trials comparing warfarin and DOACs showed comparable effectiveness without significant additional major bleeding risk. $^{5}$ In 2011, ROCKET-AF, a noninferiority randomized control trial (RCT) of 14,264 subjects showed no statistically significant difference in bleeding risk between rivaroxaban and warfarin (hazard ratio [HR] 1.04, 95\% confidence interval [CI] 0.90, 1.20). ${ }^{7}$ However, bleeding events in RCTs may differ from those in daily use due to the routine exclusion of patients with a higher risk of bleeding from many studies. ${ }^{6,7}$

Therefore, we aimed to assess bleeding risk between DOACs and warfarin in AF patients in observational studies and we also sought to determine differences between patients that were or were not previously on anticoagulants and whether early bleeding risk (within 3 months) is different than late (after 3 months) bleeding risk.

\section{Materials and Methods}

\section{Search Strategy}

A systematic literature search was conducted in the OVID MEDLINE and Embase electronic databases. The search queries were developed with a combination of Medical Subject Headings and keywords including hemorrhage, atrial fibrillation, warfarin, and DOAC (- Supplementary Material, Appendix 1). The search strategy was adapted for each database. Additional relevant studies that met the inclusion criteria were identified through bibliographies of relevant retrieved articles.

\section{Criteria for Including Studies}

We primarily aimed to include all observational studies, including cohort studies and case-control studies evaluating a DOAC and warfarin. Review articles, editorials, commentaries, conference publication, and letters to the editor were excluded. Studies were eligible if they were published between January 1990 and June 2018 (subsequently extended to January 2019), included patients aged 18 or older, and were available in English. Additionally, RCTs comparing a DOAC with warfarin were as well retrieved and included in secondary analyses to evaluate their influence on the estimates of interest.

\section{Outcome Measures}

The primary outcome was major bleeding risk. Secondary outcome was clinically relevant nonmajor bleeding (CRNMB). All studies must have used an established or validated definition of major bleeding, such as the one proposed by the
International Society of Thrombosis and Haemostasis (ISTH) or similar ${ }^{8,9}$ (-Supplementary Material, Appendix 2).

\section{Study Selection}

Two reviewers independently examined and retrieved studies by assessing the study title and abstract. Cohen's kappa coefficient ${ }^{10}$ was computed after each level of screening to assess the agreement level. Articles were included for fulltext screening if the two reviewers agreed. Disagreements were resolved in conjunction with a third reviewer by discussion and consensus. Assessments of study outcomes and study population were made before studies were included in this review.

\section{Assessment of Quality and Data Extraction}

Two reviewers independently extracted data from selected studies using a standardized data extraction form. Data regarding number of patients in each intervention, total bleeding events, and effect estimates of bleeding risk were collected. Additional data such as duration of follow-up, loss to follow-up, and patient enrollment were also recorded. Quality of the studies was evaluated using the NewcastleOttawa Scale ${ }^{11}$ for observational studies and the Jadad scale for RCTs. ${ }^{12}$

\section{Statistical Analysis}

An overall pooled HR and its $95 \% \mathrm{CI}$ for each outcome were calculated using a random effects model. ${ }^{13}$ Sensitivity analyses were conducted by study type, previous anticoagulant exposure, individual agent, type of DOAC (DTI vs. FXa inhibitors), and source of funding. All analyses were performed using Review Manager Version 5.3 (The Nordic Cochrane Centre, The Cochrane Collaboration, Copenhagen, Denmark). The generic inverse variance method ${ }^{14}$ was used to calculate an overall average effect estimate. The standard errors were obtained using the CI given by the studies and log HRs were calculated using the logarithms of the studies' HRs. Heterogeneity was assessed using the chi-squared test and the Higgins' $I^{2}$ test. $^{15}$

\section{Registration}

The protocol for the systematic review was registered on PROSPERO International Prospective Register of Systematic Reviews with the number CRD42019120468.

\section{Results}

\section{Study Selection and Characteristics}

The initial literature search identified 3,359 potentially eligible citations. After primary screening, 150 articles were eligible for full-text review and there were 35 studies $^{7,16-50}$ including $2,356,201$ patients that met the inclusion criteria and presented relevant data regarding major bleeding and clinically relevant bleeding (-Fig. 1). The studies were primarily observational including 25 retrospective cohorts, 6 prospective cohorts, and 4 RCTs (-Table 1). The focus of our review was primarily based on observational data. Results including RCTs are included in the Supplementary Material. 


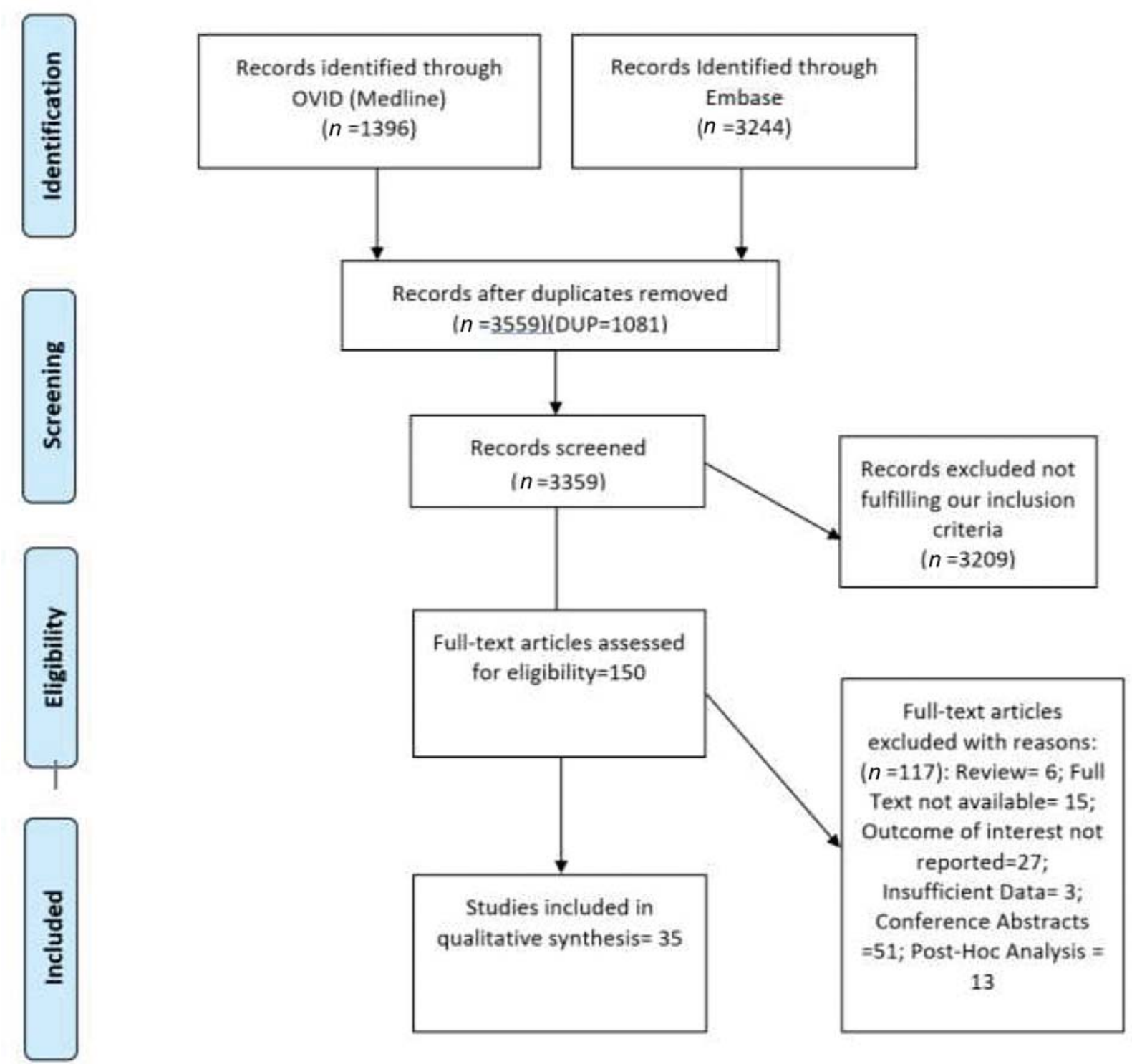

Fig. 1 PRISMA (Preferred Reporting Items for Systematic Reviews and Meta-Analyses) flow diagram summarizing the identification process of relevant studies.

\section{Study Quality}

Key quality features and quality assessment of each study are included in the Supplementary Material. All RCTs were deemed as good quality by the Jadad scale with a score of 4 or 5 (-Supplementary Material, Appendix 3). Using the Newcastle-Ottawa Scale, the prospective and retrospective cohorts varied as a result of differences in follow-up time and presences of outcome at the start of the study, but were in general adequate (-Supplementary Material, Appendix 4).

\section{Major Bleeding Events for DOACs Compared with Warfarin}

Overall, patients on DOACs were less likely to experience a bleeding event compared with warfarin (HR $0.78,95 \% \mathrm{CI} 0.71$, $0.85, p<0.001$ ). The results were consistent when analyzing patients receiving DTIs or FXa inhibitors (DTI: HR 0.76, 95\% CI 0.67, 0.87; FXa inhibitors: HR 0.79, 95\% Cl 0.69, 0.89) (-Fig. 2). However, among patients receiving FXa inhibitors there was a significant difference in the risk of bleeding according to individual drug. Among patients receiving rivaroxaban the risk of bleeding was similar to warfarin (HR $0.98,95 \%$ CI 0.91 , $1.06, p=0.60$ ), whereas in those receiving apixaban there was a $40 \%$ reduction in the risk of bleeding compared with warfarin (HR 0.60, 95\% Cl 0.50, 0.71, $p<0.001$ ) (-Fig. 3).

\section{Bleeding Risk according to Previous Anticoagulant Exposure}

Three studies ${ }^{18,36,43}$ reported information according to previous anticoagulant exposure. The overall pooled HR was 0.68 $(95 \%$ CI $0.55,0.82, p<0.001)$ in favor of patients on DOACs (-Supplementary Material, Appendix 5). In the subgroup analysis according to previous anticoagulant use the risk of bleeding was lower for DOACs compared with warfarin in both experienced population ( $\mathrm{HR} 0.70,95 \% \mathrm{Cl} 0.51,0.96$ ) and naive patients (HR 0.64, 95\% CI 0.47, 0.87). However, heterogeneity was moderate to high among both subgroups. 
Table 1 Characteristics of included studies

\begin{tabular}{|c|c|c|c|c|c|}
\hline First author $(y)$ & Type of study & $\begin{array}{l}\text { Total number } \\
\text { of patients }\end{array}$ & Type of DOACs & $\begin{array}{l}\text { Bleeding } \\
\text { definition }\end{array}$ & Funding \\
\hline Adeboyeje et al (2017) & Retrospective cohort & 44,057 & $\begin{array}{l}\text { Dabigatran, apixaban, } \\
\text { and rivaroxaban }\end{array}$ & ICD & Health insurance \\
\hline Amin et al (2017) & Prospective cohort & 180,020 & $\begin{array}{l}\text { Dabigatran, apixaban, } \\
\text { and rivaroxaban }\end{array}$ & ISTH & Pharmaceutical \\
\hline Bengtson et al (2017) & Retrospective cohort & 145,666 & Dabigatran & ICD & Research grant \\
\hline Blin et al (2019) & Prospective cohort & 103,101 & Dabigatran & ISTH & Pharmaceutical \\
\hline Bouillon et al (2015) & Retrospective cohort & 17,410 & Dabigatran and rivaroxaban & $I C D$ & No funding \\
\hline Connolly et al (2013) & Randomized control trial & 508 & Betrixaban & ISTH & Pharmaceutical \\
\hline Denas et al (2017) & Retrospective cohort & 13,480 & $\begin{array}{l}\text { Dabigatran, apixaban, } \\
\text { and rivaroxaban }\end{array}$ & ICD & Research grant \\
\hline Ellis et al (2016) & Retrospective cohort & 18,429 & Dabigatran and rivaroxaban & $I C D$ & Pharmaceutical \\
\hline Giugliano et al (2013) & Randomized control trial & 21,105 & Edoxaban & ISTH & Pharmaceutical \\
\hline Go et al (2017) & Retrospective cohort & 50,578 & Dabigatran & $I C D$ & Government \\
\hline Gorst-Rasmussen et al (2016) & Retrospective cohort & 13,450 & Rivaroxaban & $I C D$ & Nonprofit \\
\hline Graham et al (2019) & Retrospective cohort & 897,888 & $\begin{array}{l}\text { Dabigatran, apixaban, } \\
\text { and rivaroxaban }\end{array}$ & $I C D$ & Government \\
\hline Granger et al (2011) & Randomized control trial & 18,201 & Apixaban & ISTH & Pharmaceutical \\
\hline Halvorsen et al (2017) & Retrospective cohort & 32,675 & $\begin{array}{l}\text { Dabigatran, apixaban, } \\
\text { and rivaroxaban }\end{array}$ & $I C D$ & Pharmaceutical \\
\hline Hernandez et al (2015) & Retrospective cohort & 9,404 & Dabigatran & $I C D$ & Nonprofit \\
\hline Ho et al (2012) & Prospective cohort & 244 & Dabigatran & ISTH & Academia \\
\hline Huang et al (2018) & Retrospective cohort & 19,274 & Rivaroxaban & $I C D$ & Government \\
\hline Jacobs et al (2016) & Prospective cohort & 5,254 & $\begin{array}{l}\text { Dabigatran, apixaban, } \\
\text { and rivaroxaban }\end{array}$ & ICD & No funding \\
\hline Koretsune et al (2019) & Retrospective cohort & 9,212 & Dabigatran & ISTH & Pharmaceutical \\
\hline Laliberté et al (2014) & Retrospective cohort & 18,270 & Rivaroxaban & ICD & Pharmaceutical \\
\hline Larsen et al (2013) & Prospective cohort & 13,914 & Dabigatran & $I C D$ & No funding \\
\hline Larsen et al (2014) & Retrospective cohort & 11,315 & Dabigatran & ICD & Nonprofit \\
\hline Lauffenburger et al (2015) & Retrospective cohort & 64,935 & Dabigatran & ICD & Academia \\
\hline Li et al (2017) & Retrospective cohort & 153,880 & Apixaban & ICD & Pharmaceutical \\
\hline Lip et al (2016) & Retrospective cohort & 48,208 & $\begin{array}{l}\text { Dabigatran, apixaban, } \\
\text { and rivaroxaban }\end{array}$ & ICD & No funding \\
\hline Lip et al (2016) & Retrospective cohort & 15,115 & $\begin{array}{l}\text { Dabigatran, apixaban, } \\
\text { and rivaroxaban }\end{array}$ & ICD & Pharmaceutical \\
\hline Maura et al (2015) & Prospective cohort & 32,807 & Dabigatran and rivaroxaban & $\mathrm{ICD}$ & No funding \\
\hline Norby et al (2017) & Retrospective cohort & 133,740 & Rivaroxaban & ICD & Research Grant \\
\hline Patel et al (2011) & Randomized control trial & 14,264 & Rivaroxaban & ISTH & Pharmaceutical \\
\hline Russo-Alvarez et al (2018) & Retrospective cohort & 944 & Rivaroxaban & ICD & No funding \\
\hline Staerk et al (2017) & Retrospective cohort & 43,299 & $\begin{array}{l}\text { Dabigatran, apixaban, } \\
\text { and rivaroxaban }\end{array}$ & ICD & Nonprofit \\
\hline Villines et al (2015) & Retrospective cohort & 25,586 & Dabigatran & ICD & Pharmaceutical \\
\hline Vinogradova et al (2018) & Prospective cohort & 103,270 & Dabigatran & ICD & Research grant \\
\hline Wu et al (2019) & Prospective cohort & 344 & Dabigatran, rivaroxaban & Other & Not provided \\
\hline Yao et al (2016) & Retrospective cohort & 76,354 & $\begin{array}{l}\text { Dabigatran, apixaban, } \\
\text { and rivaroxaban }\end{array}$ & $I C D$ & Research grant \\
\hline
\end{tabular}

Abbreviations: DOAC, direct oral anticoagulant; ICD, International Classification of Disease; ISTH, International Society of Thrombosis and Haemostasis. 


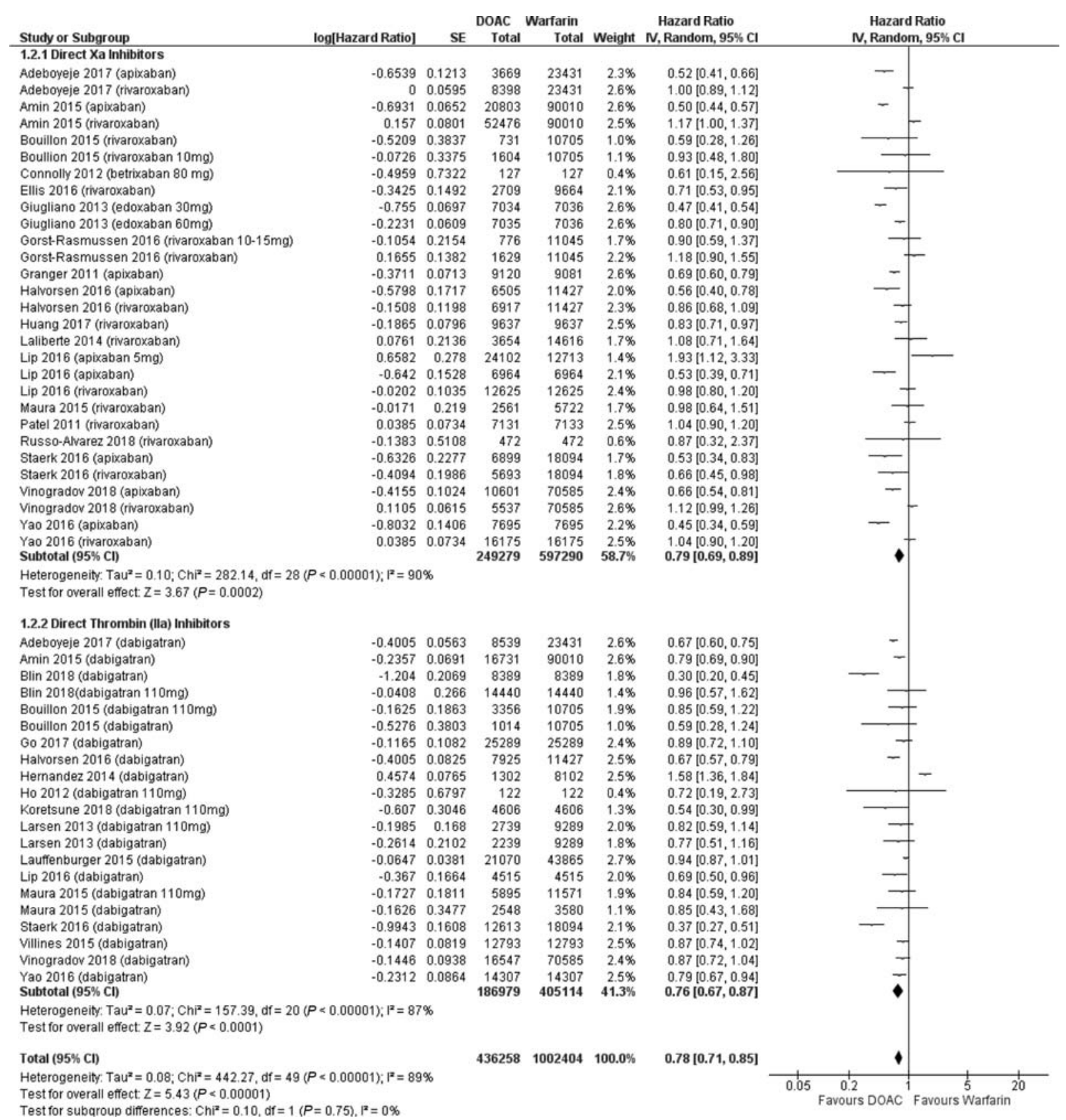

Fig. 2 Comparison of bleeding risk between direct oral anticoagulants and warfarin stratified by drug class.

\section{Short-Term and Long-Term Major Bleeding Risk}

Only one study by Norby et $\mathrm{al}^{43}$ showed that patients switching from warfarin to rivaroxaban had a higher risk of gastrointestinal bleeding in the first 90 days after switching compared with the risk after 90 days.

\section{Clinically Relevant Nonmajor Bleeding Risk}

Two studies reported data on CRNMB. The pooled average HR was 0.64 (95\% CI 0.47, 0.87, $p<0.001$ ) in favor of DOACs (-Supplementary Material, Appendix 6) with high statistical heterogeneity. Not enough studies were included in the meta-analysis for subgroup analysis for DTIs and FXa inhibitors using only data from observational studies. Using data from both RCT and observational studies, patients receiving DOACs had a lower risk of CRNMB (HR
0.73; 95\% CI 0.62, 0.86, $p<0.001$ ) in comparison to warfarin (-Supplementary Material, Appendix 7).

\section{Effect Estimate Stratified by Study and Funding Type}

There were no significant differences between effect estimates stratified by study and funding type. The pooled HR of only observational data was 0.80 (95\% CI $0.73,0.88$, $p<0.001$ ) and for RCT data was 0.72 (95\% CI 0.53, 0.97, $p=0.03$ ) (-Supplementary Material, Appendix 8). There was no statistical difference in effect estimates by study source of funding. Studies that received pharmaceutical funding had an HR of 0.77 (95\% CI 0.67, 0.88, $p<0.001$ ), while studies that received government and research aid had an HR of 0.81 (95\% CI 0.73, 0.91, p < 0.001) (-Supplementary Material, Appendix 9). 


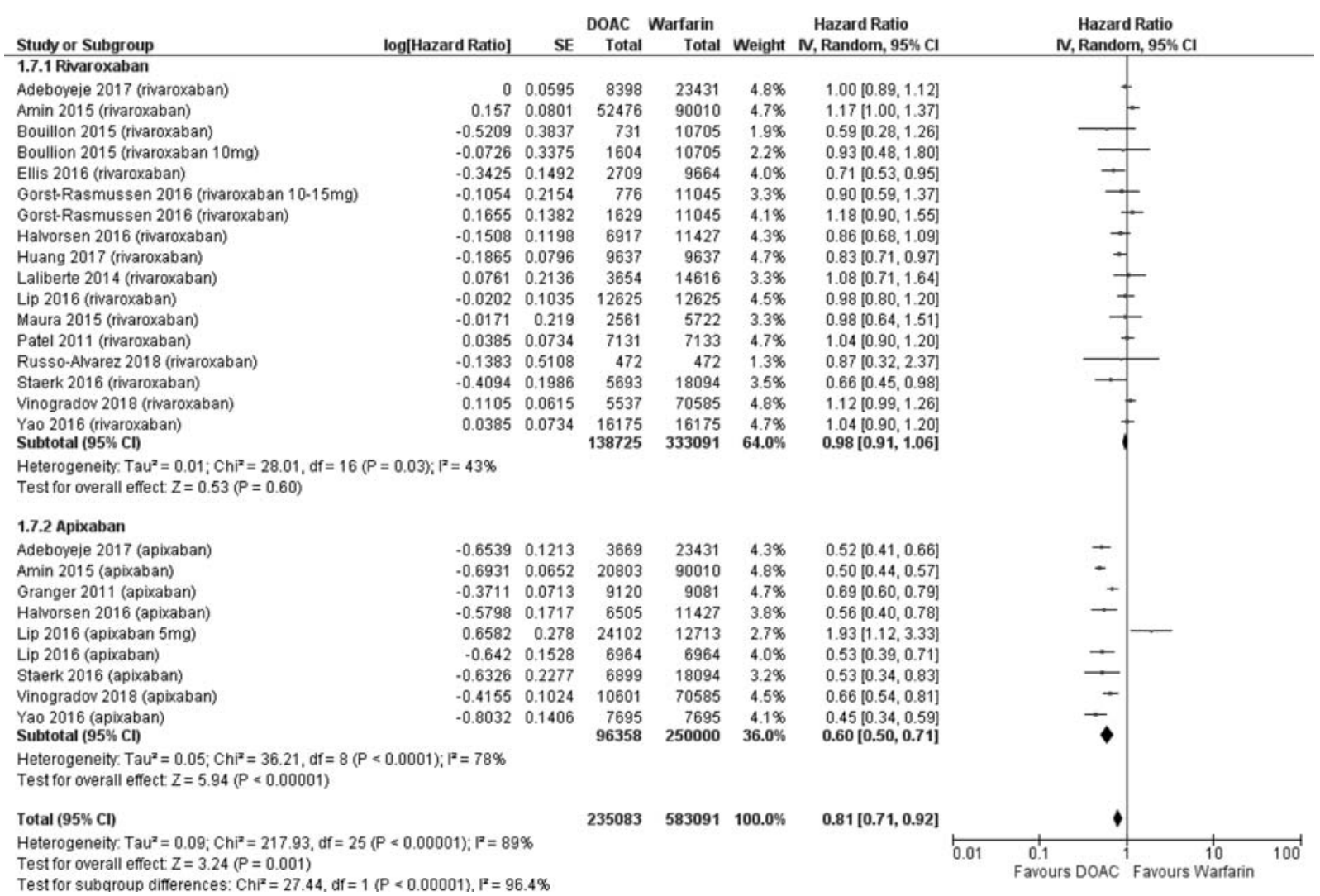

Fig. 3 Comparison of bleeding risk between direct factor Xa inhibitors and warfarin stratified by individual agent.

\section{Discussion}

This review and meta-analysis of observational studies including over 2.3 million patients showed that overall, DOACs showed a lower risk of major bleeding and CRNMB compared with warfarin. Most importantly, although the pooled effect estimate did not differ between the two drug classes, namely DTIs and FXa inhibitors, among patients receiving the latter there was a significant difference between individual agents with patients on apixaban having a significantly lower risk of bleeding compared with warfarin in contrast to patients on rivaroxaban who had a similar risk. The average pooled HR did not differ by study and funding type.

These findings are consistent with data from RCTs. Previous systematic reviews and meta-analyses of only RCTs showed results similar to the present study; however, the results were not statistically significant due to the presence of statistical heterogeneity. ${ }^{51}$ Ruff et al found that on average, AF patients in RCTs that were on DOACs are less likely to experience a major bleed in comparison to those who were on warfarin (relative risk $0.83,95 \% \mathrm{CI} 0.73,1) .{ }^{51}$ Concerns regarding power within RCTs of smaller sample size may arise because in all RCTs, major bleeding was considered as a secondary or safety outcome. Moreover, results in RCTs may not reflect the bleeding events ratios in clinical practice.

A recent systematic review of real-world bleeding risk in clinical settings had similar results and in contrast with that study our review does provide quantifiable effect estimates. ${ }^{52}$ Both studies found no significant difference in bleeding be- tween AF patients taking rivaroxaban and AF patients taking warfarin. Dabigatran and apixaban both were associated with a lower risk for bleeding. Previous independent studies have also come to similar conclusions, but in contrast, the present study provides the largest number of patients included to date and several subgroup analyses that have not been previously conducted, including the association of previous exposure to anticoagulants with the risk of bleeding. ${ }^{53,54}$ Taken together, these results provide independent confirmation of the safety profile of DOACs in AF patients and raise new and important questions to define future projects.

Our study has some limitations. First, we were unable to ascertain short-term and long-term bleeding risks because included studies varied in their reporting and follow-up. Although we aimed to determine differences of early versus late bleeding events, all studies but only one reported one bleeding risk instead of stratifying major bleeding risks before and after the 3 -month period. ${ }^{43}$ Norby et al $^{43}$ stratified their bleeding risk before and after 90 days of taking anticoagulants. Their study showed that patients switching to rivaroxaban had a higher risk of gastrointestinal bleeding in the first 90 days after switching compared with the risk after 90 days. This is an important question that needs more studies as it may lead to potential clinical interventions addressing such risk. Second, several studies did not specify loss to follow-up or duration of follow-up which limits their quality and more importantly, validity. Third, similar to previous systematic reviews and meta-analyses of RCTs, ${ }^{51,52}$ statistical heterogeneity was present in our study. Studies differed mostly in data collection, 
outcome definition, and location. Some studies used clinical data while others relied on insurance claim data. This would introduce inconsistency in reporting across studies as congruency between clinical and claims data ranges from 65 to over 90\%. ${ }^{55}$ Clinical data tends to have more details regarding patient characteristics such as laboratory results, medications, and comorbidities. There were differences in bleeding definitions used. Some studies used different revisions of the International Classification of Disease. All RCTs $7,21,24,28$ and four observational studies ${ }^{17,19,31,34}$ used the definition provided by ISTH. The differences in definition could result in the inclusion of a variation of bleeding types that were classified as major bleed. Study location ranged from North America to Europe to Asia where level of care, education, and the social economic status of the AF patients included may differ. Among the studies, different dosages were either pooled together or reported separately which would introduce more heterogeneity in interpretation. This is particularly the case for dabigatran. This variability could account for some of the insignificant differences between predetermined subgroup analyses. As a result of these inconsistencies across studies, the overall pooled estimate should be interpreted with caution. Fourth, of the included studies, there were only four that looked at differences in bleeding risk in naive and experienced $\mathrm{AF}$ patients. With DOACs being an alternative to warfarin, many AF patients are introduced to a DOAC for the first time or switched from warfarin to a DOAC. In those patients being switched from warfarin to a DOAC it is possible that preexisting conditions that increase the risk of bleeding might have been detected during the period in which patients were on warfarin, thus resulting in medical interventions to deal with such conditions and potentially resulting in a lower bleeding risk after the patients are switched. More attention should be focused on the bleeding risk between naive and experienced patients. Finally, studies that reported CRNMB were scarce as well. CRNMB still results in an increased level of care and medical interventions which is a matter of concern for patients, clinicians, and health systems.

In summary, this review showed that DOACs appeared to be associated with a lower bleeding risk compared with warfarin. Although there were no differences in bleeding outcomes between the DTIs and FXa inhibitors, among the latter, those patients on apixaban seem to have less bleeding events in comparison to warfarin while those on rivaroxaban have the same risk. Our study highlights the need for standardized definitions to better define outcomes, better data collection, and proper reporting for clinically relevant outcome assessments.

Funding

A.L.-L. is an investigator of the Canadian Venous Thromboembolism Clinical Trials and Outcomes Research (CanVECTOR) Network. This CanVECTOR Network receives grant funding from the Canadian Institutes of Health Research (Funding Reference: CDT-142654).

Conflict of Interest

None declared.

\section{References}

1 Molteni M, Polo Friz H, Primitz L, Marano G, Boracchi P, Cimminiello C. The definition of valvular and non-valvular atrial fibrillation: results of a physicians' survey. Europace 2014;16(12):1720-1725

2 Fauchier L, Philippart R, Clementy N, et al. How to define valvular atrial fibrillation? Arch Cardiovasc Dis 2015;108(10):530-539

3 Chugh SS, Havmoeller R, Narayanan K, et al. Worldwide epidemiology of atrial fibrillation: a Global Burden of Disease 2010 Study. Circulation 2014;129(08):837-847

4 Martins RP, Galand V, Colette E, et al. Defining nonvalvular atrial fibrillation: a quest for clarification. Am Heart J 2016;178:161-167

5 Jun M, Lix LM, Durand M, et al; Canadian Network for Observational Drug Effect Studies (CNODES) Investigators. Comparative safety of direct oral anticoagulants and warfarin in venous thromboembolism: multicentre, population based, observational study. BMJ 2017;359:j4323

6 Molteni M, Cimminiello C. Warfarin and atrial fibrillation: from ideal to real the warfarin affaire. Thromb J 2014;12(01):5

7 Patel MR, Mahaffey KW, Garg J, et al; ROCKET AF Investigators. Rivaroxaban versus warfarin in nonvalvular atrial fibrillation. N Engl J Med 2011;365(10):883-891

8 Kaatz S, Ahmad D, Spyropoulos AC, Schulman S; Subcommittee on Control of Anticoagulation. Definition of clinically relevant non-major bleeding in studies of anticoagulants in atrial fibrillation and venous thromboembolic disease in non-surgical patients: communication from the SSC of the ISTH.J Thromb Haemost 2015;13(11):2119-2126

9 Schulman S, Kearon C; Subcommittee on Control of Anticoagulation of the Scientific and Standardization Committee of the International Society on Thrombosis and Haemostasis. Definition of major bleeding in clinical investigations of antihemostatic medicinal products in non-surgical patients. J Thromb Haemost 2005;3(04):692-694

10 Viera AJ, Garrett JM. Understanding interobserver agreement: the kappa statistic. Fam Med 2005;37(05):360-363

11 Wells GA, Shea B, O'Connell D, et al. The Newcastle-Ottawa Scale (NOS) for assessing the quality of nonrandomized studies in metaanalyses. Available at: http://www.ohri.ca/programs/clinical_epidemiology/oxford.asp. Accessed 20 June 2018

12 Jadad AR, Moore RA, Carroll D, et al. Assessing the quality of reports of randomized clinical trials: is blinding necessary? Control Clin Trials 1996;17(01):1-12

13 DerSimonian R, Laird N. Meta-analysis in clinical trials. Control Clin Trials 1986;7(03):177-188

14 Borenstein M, Hedges LV, Higgins JPT, Rothstein HR. Introduction to Meta-Analysis. England: John Wiley and Sons Ltd.; 2009

15 Higgins JP, Thompson SG. Quantifying heterogeneity in a metaanalysis. Stat Med 2002;21(11):1539-1558

16 Adeboyeje G, Sylwestrzak G, Barron JJ, et al. Major bleeding risk during anticoagulation with warfarin, dabigatran, apixaban, or rivaroxaban in patients with nonvalvular atrial fibrillation.J Manag Care Spec Pharm 2017;23(09):968-978

17 Amin A, Keshishian A, Trocio J, et al. Risk of stroke/systemic embolism, major bleeding and associated costs in non-valvular atrial fibrillation patients who initiated apixaban, dabigatran or rivaroxaban compared with warfarin in the United States Medicare population. Curr Med Res Opin 2017;33(09):1595-1604

18 Bengtson LGS, Lutsey PL, Chen LY, MacLehose RF, Alonso A. Comparative effectiveness of dabigatran and rivaroxaban versus warfarin for the treatment of non-valvular atrial fibrillation. J Cardiol 2017;69(06):868-876

19 Blin P, Dureau-Pournin C, Cottin Y, et al. Effectiveness and safety of 110 or 150 . mg dabigatran vs. vitamin K antagonists in nonvalvular atrial fibrillation. Br J Clin Pharmacol 2019;85(02):432-441

20 Bouillon K, Bertrand M, Maura G, Blotière PO, Ricordeau P, Zureik M. Risk of bleeding and arterial thromboembolism in patients with non-valvular atrial fibrillation either maintained on a vitamin $\mathrm{K}$ antagonist or switched to a non-vitamin K-antagonist oral anticoagulant: a retrospective, matched-cohort study. Lancet Haematol 2015;2(04):e150-e159 
21 Connolly SJ, Eikelboom J, Dorian P, et al. Betrixaban compared with warfarin in patients with atrial fibrillation: results of a phase 2, randomized, dose-ranging study (Explore-Xa). Eur Heart J 2013;34(20):1498-1505

22 Denas G, Gennaro N, Ferroni E, et al. Effectiveness and safety of oral anticoagulation with non-vitamin K antagonists compared to well-managed vitamin $\mathrm{K}$ antagonists in naïve patients with nonvalvular atrial fibrillation: propensity score matched cohort study. Int J Cardiol 2017;249:198-203

23 Ellis MH, Neuman T, Bitterman H, et al. Bleeding in patients with atrial fibrillation treated with dabigatran, rivaroxaban or warfarin: a retrospective population-based cohort study. Eur J Intern Med 2016;33:55-59

24 Giugliano RP, Ruff CT, Braunwald E, et al; ENGAGE AF-TIMI 48 Investigators. Edoxaban versus warfarin in patients with atrial fibrillation. N Engl J Med 2013;369(22):2093-2104

25 Go AS, Singer DE, Toh S, et al. Outcomes of dabigatran and warfarin for atrial fibrillation in contemporary practice: a retrospective cohort study. Ann Intern Med 2017;167(12):845-854

26 Gorst-Rasmussen A, Lip GY, Bjerregaard Larsen T. Rivaroxaban versus warfarin and dabigatran in atrial fibrillation: comparative effectiveness and safety in Danish routine care. Pharmacoepidemiol Drug Saf 2016;25(11):1236-1244

27 Graham DJ, Baro E, Zhang R, et al. Comparative stroke, bleeding, and mortality risks in older Medicare patients treated with oral anticoagulants for nonvalvular atrial fibrillation. Am J Med 2019; 132(05):596-604.e11

28 Granger CB, Alexander JH, McMurray JJ, et al; ARISTOTLE Committees and Investigators. Apixaban versus warfarin in patients with atrial fibrillation. N Engl J Med 2011;365(11):981-992

29 Halvorsen S, Ghanima W, Fride Tvete I, et al. A nationwide registry study to compare bleeding rates in patients with atrial fibrillation being prescribed oral anticoagulants. Eur Heart J Cardiovasc Pharmacother 2017;3(01):28-36

30 Hernandez I, Baik SH, Piñera A, Zhang Y. Risk of bleeding with dabigatran in atrial fibrillation. JAMA Intern Med 2015;175(01):18-24

31 Ho JC, Chang AM, Yan BP, Yu CM, Lam YY, Lee VW. Dabigatran compared with warfarin for stroke prevention with atrial fibrillation: experience in Hong Kong. Clin Cardiol 2012;35(12):E40-E45

32 Huang HY, Lin SY, Cheng SH, Wang CC. Effectiveness and safety of different rivaroxaban dosage regimens in patients with nonvalvular atrial fibrillation: a nationwide, population-based cohort study. Sci Rep 2018;8(01):3451

33 Jacobs V, May HT, Bair TL, et al. Long-term population-based cerebral ischemic event and cognitive outcomes of direct oral anticoagulants compared with warfarin among long-term anticoagulated patients for atrial fibrillation. Am J Cardiol 2016;118 (02):210-214

34 Koretsune Y, Yamashita T, Yasaka M, et al. Comparative effectiveness and safety of warfarin and dabigatran in patients with non-valvular atrial fibrillation in Japan: a claims database analysis. J Cardiol 2019; 73(03):204-209

35 Laliberté F, Cloutier M, Nelson WW, et al. Real-world comparative effectiveness and safety of rivaroxaban and warfarin in nonvalvular atrial fibrillation patients. Curr Med Res Opin 2014;30 (07):1317-1325

36 Larsen TB, Gorst-Rasmussen A, Rasmussen LH, Skjøth F, Rosenzweig M, Lip GY. Bleeding events among new starters and switchers to dabigatran compared with warfarin in atrial fibrillation. Am J Med 2014;127(07):650-656.e5

37 Larsen TB, Rasmussen LH, Skjøth F, et al. Efficacy and safety of dabigatran etexilate and warfarin in "real-world" patients with atrial fibrillation: a prospective nationwide cohort study. J Am Coll Cardiol 2013;61(22):2264-2273

38 Lauffenburger JC, Farley JF, Gehi AK, Rhoney DH, Brookhart MA, Fang G. Effectiveness and safety of dabigatran and warfarin in real-world US patients with non-valvular atrial fibrillation: a retrospective cohort study. J Am Heart Assoc 2015;4(04):4
39 Li XS, Deitelzweig S, Keshishian A, et al. Effectiveness and safety of apixaban versus warfarin in non-valvular atrial fibrillation patients in "real-world" clinical practice. A propensity-matched analysis of 76,940 patients. Thromb Haemost 2017;117(06):1072-1082

40 Lip GY, Keshishian A, Kamble S, et al. Real-world comparison of major bleeding risk among non-valvular atrial fibrillation patients initiated on apixaban, dabigatran, rivaroxaban, or warfarin. A propensity score matched analysis. Thromb Haemost 2016;116(05):975-986

41 Lip GY, Pan X, Kamble S, et al. Major bleeding risk among nonvalvular atrial fibrillation patients initiated on apixaban, dabigatran, rivaroxaban or warfarin: a "real-world" observational study in the United States. Int J Clin Pract 2016;70(09):752-763

42 Maura G, Blotière PO, Bouillon K, et al. Comparison of the shortterm risk of bleeding and arterial thromboembolic events in nonvalvular atrial fibrillation patients newly treated with dabigatran or rivaroxaban versus vitamin K antagonists: a French nationwide propensity-matched cohort study. Circulation 2015; 132(13):1252-1260

43 Norby FL, Bengtson LGS, Lutsey PL, et al. Comparative effectiveness of rivaroxaban versus warfarin or dabigatran for the treatment of patients with non-valvular atrial fibrillation. BMC Cardiovasc Disord 2017;17(01):238

44 Russo-Alvarez G, Martinez KA, Valente M, et al. Thromboembolic and major bleeding events with rivaroxaban versus warfarin use in a real-world setting. Ann Pharmacother 2018;52(01):19-25

45 Staerk L, Fosbøl EL, Lip GYH, et al. Ischaemic and haemorrhagic stroke associated with non-vitamin $\mathrm{K}$ antagonist oral anticoagulants and warfarin use in patients with atrial fibrillation: a nationwide cohort study. Eur Heart J 2017;38(12):907-915

46 Villines TC, Schnee J, Fraeman K, et al. A comparison of the safety and effectiveness of dabigatran and warfarin in non-valvular atrial fibrillation patients in a large healthcare system. Thromb Haemost 2015;114(06):1290-1298

47 Vinogradova Y, Coupland C, Hill T, Hippisley-Cox J. Risks and benefits of direct oral anticoagulants versus warfarin in a real world setting: cohort study in primary care. BMJ 2018;362:k2505

$48 \mathrm{Wu}$ S, Xie S, Xu Y, et al. Persistence and outcomes of non-vitamin K antagonist oral anticoagulants versus warfarin in patients with non-valvular atrial fibrillation. J Clin Nurs 2019;28(910):1839-1846

49 Yao X, Abraham NS, Sangaralingham LR, et al. Effectiveness and safety of dabigatran, rivaroxaban, and apixaban versus warfarin in nonvalvular atrial fibrillation. J Am Heart Assoc 2016;5(06):5

50 Yavuz B, Ayturk M, Ozkan S, et al. A real world data of dabigatran etexilate: multicenter registry of oral anticoagulants in nonvalvular atrial fibrillation. J Thromb Thrombolysis 2016;42(03):399-404

51 Ruff CT, Giugliano RP, Braunwald E, et al. Comparison of the efficacy and safety of new oral anticoagulants with warfarin in patients with atrial fibrillation: a meta-analysis of randomised trials. Lancet 2014;383(9921):955-962

52 Briere JB, Bowrin K, Coleman C, et al. Real-world clinical evidence on rivaroxaban, dabigatran, and apixaban compared with vitamin $\mathrm{K}$ antagonists in patients with nonvalvular atrial fibrillation: a systematic literature review. Expert Rev Pharmacoecon Outcomes Res 2019;19(01):27-36

53 Douros A, Durand M, Doyle CM, Yoon S, Reynier P, Filion KB. Comparative effectiveness and safety of direct oral anticoagulants in patients with atrial fibrillation: a systematic review and metaanalysis of observational studies. Drug Saf 2019;42(10):1135-1148

54 Ntaios G, Papavasileiou V, Makaritsis K, Vemmos K, Michel P, Lip GYH. Real-world setting comparison of nonvitamin-K antagonist oral anticoagulants versus vitamin-K antagonists for stroke prevention in atrial fibrillation: a systematic review and metaanalysis. Stroke 2017;48(09):2494-2503

55 Roos LL, Sharp SM, Cohen MM. Comparing clinical information with claims data: some similarities and differences. J Clin Epidemiol 1991;44(09):881-888 